\title{
Solar Energy Generation Using Agriculture Cultivated Lands
}

\author{
T. Harinarayana ${ }^{1}$, K. Sri Venkata Vasavi ${ }^{* *}$ \\ ${ }^{1}$ Gujarat Energy Research and Management Institute, Gandhinagar, India; ${ }^{2}$ Medha College of Engineering, Bibinagar, India. \\ Email: harinarayana@germi.res.in,
}

Received December $6^{\text {th }}, 2013$; revised January $6^{\text {th }}, 2014$; accepted January $13^{\text {th }}, 2014$

Copyright (C) 2014 T. Harinarayana, K. Sri Venkata Vasavi. This is an open access article distributed under the Creative Commons Attribution License, which permits unre stricted us e, di stribution, and reproduction in any medium, provi ded the or iginal w ork is properly cited. In accordance of the Creative Commons Attribution License all Copyrights (C) 2014 are reserved for SCIRP and the owner of the intellectual property T. Harinarayana, K. Sri Venkata Vasavi. All Copyright (C 2014 are guarded by law and by SCIRP as a guardian.

\begin{abstract}
Generation of electricity using solar PV is picking up in India in a big way in recent years. It needs a clear direction such that it can optimally be utilized and the benefits, without being concentrated in a few locations, can reach the majority of poor population as well. Indian farmers, for the last few decades are affected in terms of availability of electrical power. The present study suggests the use of fertile and cultivated land with about $5 \mathbf{m}$ elevated structure with solar panels. It creates shade on the crops. In the present study, the shade effect on the crops below the structure has been examined systematically through modeling studies. Different solar panel design configurations are suggested such that the crops or plants below, on the ground surface, can also be grown without a ny reduction in their $y$ ield. The ef fect of the el evated s tructure on the neighboring lands is a lso e $x$ amined. It is shown that the present concept can easily be implemented in India, perhaps in the world, at all the locations such that power $c$ an be generated us ing farmer's own land for his own be nefit, perhaps with some profit to him. The present concept, if implemented, also red uces the huge cost involved in establishing the network of transmission and distribution lines.
\end{abstract}

\section{KEYWORDS}

Energy; Shade; Farmer; Cultivation; Cities; Land

\section{Introduction}

Among different forms of renewable energy, solar PV is growing at a very high rate of $30 \%-40 \%$. During 2006, the w orld annual solar PV production is close to $2 \mathrm{GW}$ with $5 \mathrm{t}$ imes i ncrease in $2009 \mathrm{c}$ rossing $10 \mathrm{GW}$. The availability of f ree natural resource $w$ ith $m$ atured technology, long term reliability are some of the factors why many c ountries have decided to go in a big way with major $t$ argets in the y ears to co me $[1,2]$. F or example, China is planning to generate $40 \mathrm{GW}$ of e lectricity by 2015, while India just crossed $1 \mathrm{GW}$ mark recently during 2013 with an aim to reach $20 \mathrm{GW}$ grid connected and $2 \mathrm{GW}$ off grid by the year 2022 [3,4]. If India decides to grow $9 \%$ GDP for the next 20 years, then the electrical power needs to be increased from the present generation

\footnotetext{
"Corresponding author.
}

of $212 \mathrm{GW}$ to $1207 \mathrm{GW}$ by the year 2031 . This is nearly 5.7 times more electricity of present day generation. Out of $212 \mathrm{G} \mathrm{W}, 140 \mathrm{GW}$ i s c oming f rom non -renewable energy resources, close to $69 \%$ and $65 \mathrm{GW}$ is being produced from renewable resources, close to $31 \%$. The renewable s ources include hydro-power $(40 \mathrm{GW})$, smallhydro (3.7 GW), bio-mass (1.26 GW), wind (19.8 GW), PV-solar (1.98 GW) [2]. In order to reach the target of $1207 \mathrm{GW}$ of power by the year 2031, one needs to generate $838 \mathrm{GW}$ from non-renewable sources and $371 \mathrm{GW}$ from r enewable s ources. This is based on simple ar ithmetic o $\mathrm{fm}$ ultiplication o f a $11 \mathrm{t}$ he power generation through di fferent fuels by 5.7. This type of model demands huge amount of hydrocarbons including coal to be imported from ot her $\mathrm{c}$ ountries. I $\mathrm{t} \mathrm{m}$ akes I ndia a lways depend on other countries for energy needs. Thus this is not a smart solution. 
In r ecent y ears, a few c ountries have taken a s trong decision to generate their total energy demand only from renewable energy resources. F or example, S cotland and Philippines a re $\mathrm{m}$ aking $\mathrm{c}$ oncerted plans $\mathrm{t} \mathrm{o} \mathrm{m}$ eet $\mathrm{t}$ heir energy de mand (above 50,000 M W) from $r$ enewable energy alone by the year $2020[5,6]$. Similarly Nigeria is planning in a big way to use the renewable energy [7]. In the direction of $100 \%$ renewable energy generation, India can generate large a mount of s olar PV power. With an as sumption that 5 acres of land can produce approximately $1 \mathrm{MW}$ of electricity, the total Indian 1 and a rea can produce $32,499 \mathrm{GW}$ of electricity. This means about $1 / 27$ th of the Indian 1 and $m$ ass $c$ an generate ou $r 2031$ target of $1207 \mathrm{GW}$ of electricity. This demands about 6 million a cres of $\mathrm{f}$ ree 1 and for placing the s olar panels. This much free/waste land does not exist. In view of this, one needs to device innovative ways to use the existing land in a more effective way.

In this direction a couple of new ideas have be en recently pu blished [ 8,9]. One of the $n$ ew c oncept [ 8] is based on the solar panels placed one above the other at a fixed he ight of a bout $3 \mathrm{~m}$ depending u pon the di mensions of the solar panels. This way the area necessary for a s ingle layer solar panel to generate, say $\mathrm{X}$ am ount of energy, can generate $1.7 \mathrm{X}$ amount of en ergy using the same ar ea. $\mathrm{T}$ he $\mathrm{r}$ oof-tops and va rious buildings a nd houses in the cities and towns can effectively and more economically be used from this concept. In a nother innovative idea, the concept of using the national road way network across India is suggested. In this research paper [9], through m odeling s tudies, the u se of national high way along A hmadabad-Rajkot and a lso a long Ah medabad-Vadodara has been demonstrated.

In the present paper, another concept is introduced. As on today solar parks, solar farms, have been planned to establish at different locations where the land is un-used or barren. Due to increase in population, the a vailability of such land is only 6\% (97 million acres). Additionally, such type of land is located far away from major cities, towns, industrial locations etc. This demands creation of long $t$ ransmission 1 ines from s olar pa rks. E ven if we create such large infrastructure, the use of power is concentrated towards industries and cities. In India most of the $\mathrm{p}$ opulation $\mathrm{l}$ ives i $\mathrm{n} \mathrm{v}$ illages, $\mathrm{f}$ ar a way f rom major cities and towns. Their main livelihood is through cultivation. This way most of our Indian farmers have been suffering from lack of electricity. This scenario has been continuing for the last several decades and little has been changed to improve the situation. The new concept discussed in this paper will provide one time solution that greatly helps the farmer in the villages on one hand and saving 1 arge e xpenditure on the de velopment of huge infrastructure to the government on the other side. Our study is based on the use of fertile land. In this concept, the key issues involved in implementation are discussed and a road map is provided to increase energy generation and also to make the farmer community with comfort.

\section{Methodology}

The present study is carried out using PV-Syst s oftware [10]. Details of the software program us ed in our study have been discussed in the previous papers [8,9]. In all the modeling studies, we have taken 1 acre (4047 sq m, nearly $63 \times 63 \mathrm{~m}$ ) of land in s quare shape as one unit. The schematic diagram shown in Figure 1 explains the configuration followed in the present study.

In our study the main theme is to estimate the effect of the shade on the crops at the ground surface due to the solar $\mathrm{p}$ anels a bove $\mathrm{t}$ he ground. The s olar $\mathrm{p}$ anels a re placed on an elevated structure at $5 \mathrm{~m}$ above the ground. As it is well known to all that sunlight is the main source for good growth and health of all the plant life. For this purpose, $d$ ifferent types of $c$ onfiguration a re analyzed systematically through modeling studies and recommend a design for solar panels such that it has minimum effect on crops. S imilar study has be en carried o ut for gr een house cultivation $[11,12]$. B efore explaining eac $h$ cas e, the basic configuration of a typical case is described below.

Case 1: This is a typical case. In this case 36 solar panels are arranged in a row along $63 \mathrm{~m}$ with zero inclination (horizontal) with a total of 1944 solar panels covering one acre of land. There are 18 rows lie adjacent to the other along $63 \mathrm{~m}$ length wise. Each row contains a set of 3 solar panels. Such type of configuration helps to estimate the possible total potential of s olar energy generation in a ny a rea (Figure 1). This c onfiguration is fixed

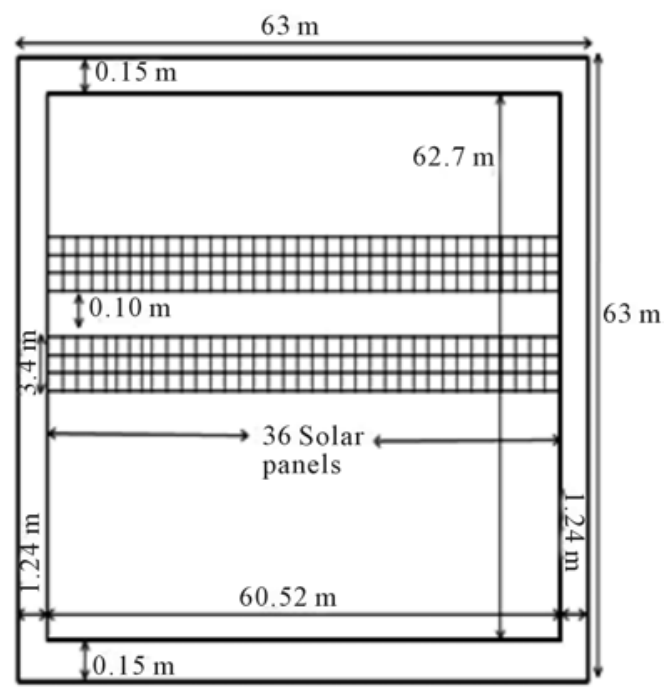

Figure 1. Typical field design of s olar panels in one acre of land. 
and the modeling is c arried out for one a cre of land in various locations. I nitially, m ajor c ities a re c onsidered. Later the study has also been carried out by varying the latitude.

Firstly, t he c onfiguration in c ities is described. T he important $p$ arameters $r$ elated to A hmedabad City have been tabulated in Table 1.

For this purpose, $\mathrm{p}$ arameters 1 ike 1 atitude, longitude, average global i rradiation, a verage t emperature et c. for major ci ties ar e i dentified. T he P V m odule $\mathrm{p}$ arameters assumed for all the cities in all the cases are same and the details are described in Table 2.

The major cities considered in our study are Mumbai, Ahmedabad, New Delhi, Bangalore, Chennai, Hyderabad, Gowhati a nd Kolkata c overing M aharashtra, Gujarat, Delhi, Karnataka, Tamil Nadu, Andhra Pradesh, Assam and West Bengal states respectively. As explained before, in our modeling one acre of land with solar panels distributed on the $\mathrm{g}$ round h orizontally in flat c ondition is considered. Other $\mathrm{p}$ arameters for $\mathrm{d}$ ifferent cities are $\mathrm{t}$ abulated in Table 3 .

As mentioned before, the number solar panels placed in one acre of land in all the cities are fixed at 1944. Results are presented in the next section.

In a similar way, a study has a lso been made on the variation of solar energy ge neration wi th 1 atitude. The first location chosen is the southernmost loc ation of India-Kanyakumari-with $8.08^{\circ} \mathrm{N} 1$ atitude, $77.57^{\circ} \mathrm{E} 1$ ongitude and $3 \mathrm{~m}$ altitude. The data of latitude, longitude and altitude for different locations are taken from google earth pro. ver. 7.0 [13]. We have computed the energy generation ag ain $r$ estricting the ar ea to 1 acre of $l$ and keeping a ll the s olar panels in flat h orizontal c ondition (Figure 2(a)) with fixed number of 1944 panels. By fixing the longitude as $77.57^{\circ} \mathrm{E}$ and for every two degrees of latitude, the solar energy generation has been computed. This way, we have considered latitudes 8.08, 10, 12, 14, $16,18,20,22,24,26,28,30$ and 32 de grees. The station na mes gi ven a re L $8, \mathrm{~L} 10$ e tc. a nd ot her parame- ters are as shown in Table 4.

As explained earlier, in a ll o ur m odeling studies the unit of 1 and a rea c onsidered is one a cre. The di fferent parameters for modeling a re shown in Tables 1 and 2 . More detailed analysis is made for allocation of one acre of land chosen in Ahmedabad in Gujarat, India. The average $g$ lobal s olar radiation data co nsidered for all the cities and different places of India is to compute the effect of shades during the years 1983-1993 [14]. Based on the dimension of the solar panels and tilt, the number of panels in one acre of 1 and will $v$ ary. The $p$ arameter of

Table 1. Parameters of ahmedabad.

\begin{tabular}{cc}
\hline Name of the site & Ahmedabad \\
\hline Latitude (degrees) & $23.067^{\circ} \mathrm{N}$ \\
Longitude (degrees) & $72.633^{\circ} \mathrm{E}$ \\
Altitude (meter) & $55 \mathrm{~m}$ \\
Radiation & $1981-2000$ \\
Azimuth & $0^{\circ}$ \\
Inclination & $25^{\circ}$ \\
\hline
\end{tabular}

Table 2. PV module specifications.

\begin{tabular}{cc}
\hline Number of solar panels & 1944 \\
\hline Area of the field (land) & 1 Acre $(\sim=4047 \mathrm{Sq} \mathrm{m})(63 \times 63 \mathrm{~m})$ \\
$\begin{array}{c}\text { Active area of the modules. } \\
\text { (sensitive PV area) }\end{array}$ & $3219 \mathrm{~m}^{2}$ \\
Name of the manufacturer & DelSolar \\
Technology & Si-polycrystalline \\
Year & 2010 \\
Pmpp & $230.3 \mathrm{~W}$ \\
Impp & $7.72 \mathrm{~A}$ \\
Vmpp & $29.8 \mathrm{~V}$ \\
Orientation & $0^{\circ}$ (exactly south)
\end{tabular}

Table 3. Energy generation table for different cities.

\begin{tabular}{|c|c|c|c|c|c|c|c|c|}
\hline Places/Attribute & Mumbai & Bangalore & Ahmedabad & Chennai & Hyderabad & Delhi & Guwahati & Kolkata \\
\hline $\begin{array}{l}\text { Annual global irradiance } \\
\qquad\left(\mathrm{kwh} / \mathrm{m}^{2} \cdot \mathrm{mth}\right)\end{array}$ & 2153.2 & 1917 & 1906 & 1908.1 & 1890.3 & 1845.7 & 1713.1 & 1704.9 \\
\hline Average temperature & $26.7^{\circ} \mathrm{C}$ & $24.7^{\circ} \mathrm{C}$ & $27.4^{\circ} \mathrm{C}$ & $27.7^{\circ} \mathrm{C}$ & $27.0^{\circ} \mathrm{C}$ & $23.8^{\circ} \mathrm{C}$ & $18.5^{\circ} \mathrm{C}$ & $25.7^{\circ} \mathrm{C}$ \\
\hline Longitude & $72.9^{\circ} \mathrm{E}$ & $77.59^{\circ} \mathrm{E}$ & $72.58^{\circ} \mathrm{E}$ & $80.3^{\circ} \mathrm{E}$ & $78.5^{\circ} \mathrm{E}$ & $77.2^{\circ} \mathrm{E}$ & $91.7^{\circ} \mathrm{E}$ & $88.4^{\circ} \mathrm{E}$ \\
\hline Latitude & $19.08^{\circ} \mathrm{N}$ & $12.98^{\circ} \mathrm{N}$ & $23.03^{\circ} \mathrm{N}$ & $13.05^{\circ} \mathrm{N}$ & $17.4^{\circ} \mathrm{N}$ & $28.6^{\circ} \mathrm{N}$ & $26.2^{\circ} \mathrm{N}$ & $22.6^{\circ} \mathrm{N}$ \\
\hline Altitude & $12 \mathrm{~m}$ & $913 \mathrm{~m}$ & $52 \mathrm{~m}$ & $10 \mathrm{~m}$ & $509 \mathrm{~m}$ & $216 \mathrm{~m}$ & $145 \mathrm{~m}$ & $7 \mathrm{~m}$ \\
\hline $\begin{array}{c}\text { Energy generated on the } \\
1 \text { acer land }(\mathrm{KWh})\end{array}$ & 766,703 & 693,226 & 678,574 & 677,621 & 673,364 & 668,824 & 644,116 & 615,903 \\
\hline
\end{tabular}


Table 4. Energy generation and average temperature at different latitudes.

\begin{tabular}{|c|c|c|c|c|c|c|c|c|}
\hline S.No & Latitude & Longitude & Altitude & Name & $\begin{array}{l}\text { Global Irradiance } \\
\left(\mathrm{KWh} \cdot \mathrm{m}^{2} / \mathrm{mth}\right)\end{array}$ & $\begin{array}{c}\text { Average } \\
\text { temperature }\left({ }^{\circ} \mathrm{C}\right)\end{array}$ & $\begin{array}{l}\text { Energy generated at the } \\
\text { output array (KWh) }\end{array}$ & Rank \\
\hline 1 & $8.08^{\circ} \mathrm{N}$ & $77.57^{\circ} \mathrm{E}$ & $3 \mathrm{~m}$ & L 8 & 1793.2 & 26.3 & 644,377 & 13 \\
\hline 2 & $10.00^{\circ} \mathrm{N}$ & $77.57^{\circ} \mathrm{E}$ & $291 \mathrm{~m}$ & L 10 & 1823.2 & 24.9 & 660,829 & 11 \\
\hline 3 & $12.00^{\circ} \mathrm{N}$ & $77.57^{\circ} \mathrm{E}$ & $823 \mathrm{~m}$ & L 12 & 1917.2 & 24.7 & 693,267 & 5 \\
\hline 4 & $14.00^{\circ} \mathrm{N}$ & $77.57^{\circ} \mathrm{E}$ & $621 \mathrm{~m}$ & L 14 & 1950.6 & 26.5 & 697,287 & 3 \\
\hline 5 & $16.00^{\circ} \mathrm{N}$ & $77.57^{\circ} \mathrm{E}$ & $348 \mathrm{~m}$ & L 16 & 1956.2 & 27.4 & 694,546 & 4 \\
\hline 6 & $18.00^{\circ} \mathrm{N}$ & $77.57^{\circ} \mathrm{E}$ & $544 \mathrm{~m}$ & L 18 & 1934 & 27.2 & 687,312 & 6 \\
\hline 7 & $20.00^{\circ} \mathrm{N}$ & $77.57^{\circ} \mathrm{E}$ & $406 \mathrm{~m}$ & L 20 & 1907.6 & 27.2 & 679,083 & 7 \\
\hline 8 & $22.00^{\circ} \mathrm{N}$ & $77.57^{\circ} \mathrm{E}$ & $664 \mathrm{~m}$ & L 22 & 1872.6 & 26.1 & 670,948 & 8 \\
\hline 9 & $24.00^{\circ} \mathrm{N}$ & $77.57^{\circ} \mathrm{E}$ & $473 \mathrm{~m}$ & L 24 & 1846.9 & 25.6 & 664,337 & 10 \\
\hline 10 & $26.00^{\circ} \mathrm{N}$ & $77.57^{\circ} \mathrm{E}$ & $398 \mathrm{~m}$ & L 26 & 1830.8 & 25.3 & 659,656 & 12 \\
\hline 11 & $28.00^{\circ} \mathrm{N}$ & $77.57^{\circ} \mathrm{E}$ & $184 \mathrm{~m}$ & L 28 & 1845.7 & 23.8 & 669,950 & 9 \\
\hline 12 & $30.00^{\circ} \mathrm{N}$ & $77.57^{\circ} \mathrm{E}$ & $279 \mathrm{~m}$ & L 30 & 1931.8 & 22.3 & 704,203 & 2 \\
\hline 13 & $32.00^{\circ} \mathrm{N}$ & $77.57^{\circ} \mathrm{E}$ & $4432 \mathrm{~m}$ & L 32 & 1926 & 7.9 & 760,686 & 1 \\
\hline
\end{tabular}

solar panels used in each case is shown in Figure 2(b). More d etails are e xplained below for eac $\mathrm{h}$ c onfiguration-case wise.

Case 2: In this case all the solar panels are arranged in a typical fashion at a location in A hmedabad, Gujarat, India. The inclination of all the solar panel is fixed at $25^{\circ}$ of acing south direction. Three different pitch values (3.8, 7.6 and $11.4 \mathrm{~m}$ ) are assumed for computation. The pitch value is the distance between the adjacent rows of solar panels as shown in Figure 2(b). In case-2 to 9, the average global irradiation values for the year 1981 to 2000 as detailed in [8] are considered for computation.

Case 3: In this case, the solar panels are arranged like a c hess board pa ttern a s s hown in Figure 2(c). E ach square contains six solar panels $(2 \times 3)$. The solar panels are arranged in a square area facing south with $25^{\circ}$ inclination in s uch a m anner that there will be a ir g ap b etween eac $h$ s quare with same dimensions that of s olar panels. The above (Figures 2(a)-(c)) three cas es considered ar e carried to es timate the power generation with different solar panel configurations.

In the next three cas es-cases 4, 5 and 6, a nalysis is made a ssuming the shade (blind) with the same dimension and configuration as that of solar panels but elevated at $5 \mathrm{~m}$ as considered in the previous three cases 1 to 3 . On the ground, the solar panels lie in flat orientation with zero an gle, as $\mathrm{d}$ iscussed in case- 1 a nd a lso $\mathrm{s}$ hown i $\mathrm{n}$ Figures 2(d)-(f). Mod elling on such type of configuration helps t $\mathrm{o}$ estimate the a mount of $\mathrm{s}$ unlight or $\mathrm{s}$ olar radiation that falls on $t$ he ground below, once we place the solar panels above the ground. Since it is difficult to estimate the amount of sunlight that falls on the ground, we estimate the energy generation due to solar radiation. For the purpose of e stimating the solar radiation, it is necessary to compute the e nergy g eneration on the panels. It is as sumed that at a location, the en ergy generation is proportional to the solar radiation. This is a reasonable assumption as more solar radiation at a location, normally gives m ore s olar energy a nd vice versa. The energy generation also depends on other parameters like temperature. Accordingly, modeling has been carried out for the following three cases also.

Case 4: In this case, blank (blind) shade with zero inclination is placed over the solar panels at a height of 5 $\mathrm{m}$ ab ove the ground s urface. $\mathrm{T}$ he s olar $\mathrm{p}$ anels a re a $\mathrm{r}-$ ranged also with zero inclination with the same configuration on the ground surface as that of case 1 . The configuration is presented as a s chematic diagram in Figure 2(d).

Case 5: In this case, the solar panels lie on the ground with zero inclination while the shade or blind is located at $5 \mathrm{~m}$ above the ground. The blind shades are arranged in such a manner that is lined up in a row with $25^{\circ}$ inclination with a separation of $3.8,7.6$ and $11.4 \mathrm{~m}$ between the rows. The idea here is to compute the solar radiation on the ground if we place the solar panels a bove the ground with the same configuration.

Case 6: In this case also the solar panels are arranged on $\mathrm{t}$ he $\mathrm{g}$ round $\mathrm{w}$ ith $\mathrm{z}$ ero i nclination a nd the $\mathrm{s}$ hade or blind is located above them at $5 \mathrm{~m}$ height. The configuration of the s hade is 1 ike a c hess b oard pattern. This means the $s$ hade $p$ anels a re in o ne s quare an $\mathrm{d}$ ai $\mathrm{r}$ gap with the same dimensions adjacent to it. In each square, a total of 6 panels are placed. The idea here is to compute 


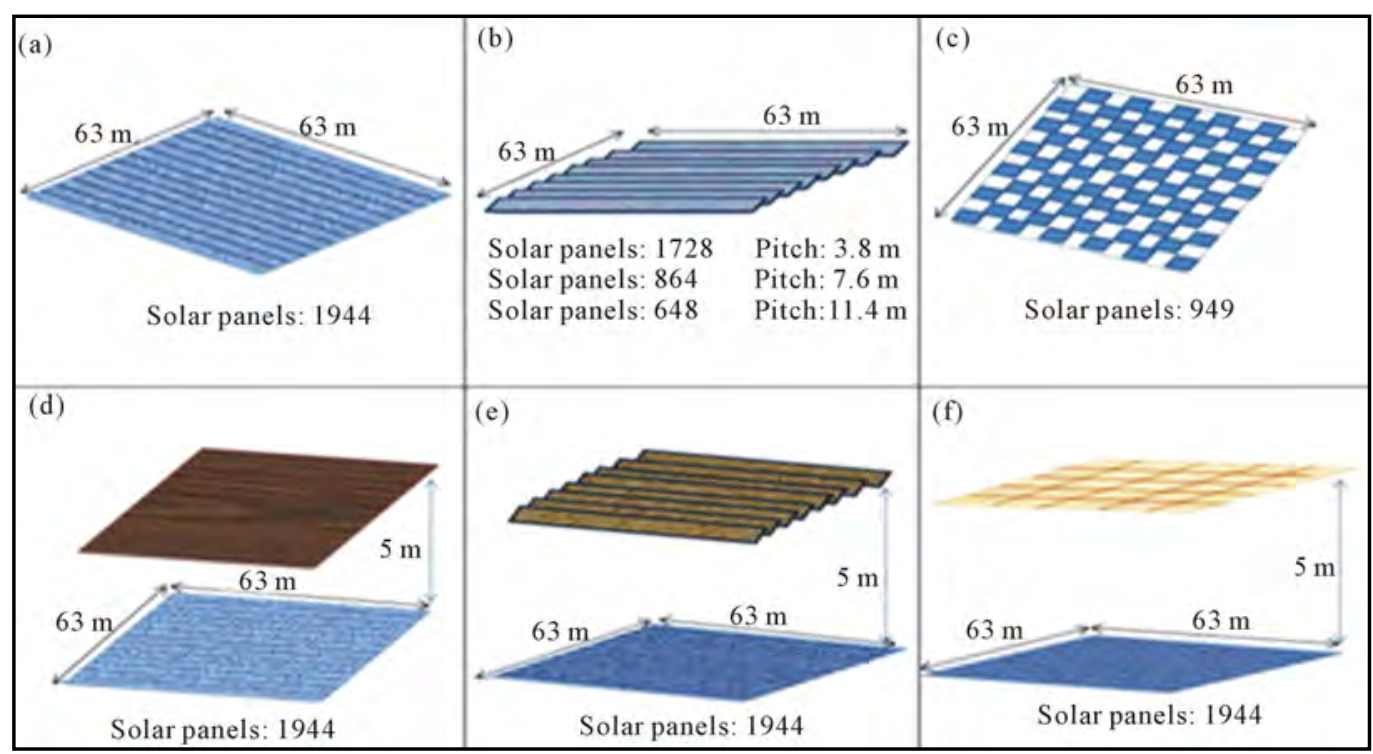

Figure 2. Schematic diagram for the cases "a" to "f". (a) Solar panels (1944 number) placed on the ground with zero inclination. (b) Solar panels on the ground with $25^{\circ}$ inclination with different pitch values (3.8/7.6/11.4 m). (c) Solar panels on the ground with $25^{\circ}$ inclination like a chess board pattern. (d) Solar panels on the ground with zero inclination and shade of 5 meter above the ground with same dimensions as that of solar panels in case-a. (e) Solar panels on the ground with zero inclination and shade of 5 meter height with dimension of the shade similar to that of solar panels in the case-b. (f) Solar panels on the ground with zero inclination and shade of 5 meter height with dimension of the shade similar to that of solar panels in the case-c.

the energy generation which in turn gives information of the solar radiation on the ground if $\mathrm{w}$ e place the solar panels above at $5 \mathrm{~m}$ with the same configuration.

The ab ove three cas es 4,5 and 6 provide im portant data on the solar energy ge neration and in turn provide information on the solar radiation due to the shade that lie above the ground. By observing the a mount of solar radiation that reaches the ground surface, one can decide the a mount of $\mathrm{s}$ unlight received by di fferent $\mathrm{c}$ rops o $\mathrm{r}$ plants. Based on the a mount of solar radiation, one c an decide on $t$ he $t$ ype of $c$ onfiguration $t$ hat $c$ an be used safely and profitably for the cultivation.

In all the above cases 1 to 6 , we have concentrated on the computation of energy on different solar panel configurations and the effect of shade above the ground. This means we have computed the effects of different shades on the owner's land (A in Figure 3). Since the land we are planning to install the solar panels are fertile and cultivated, it is likely that neighbor's may object for such a construction. Their objection may be based on possible reduction of the yield from their crops due to the shade. This demands to es timate and provide scientific as sessment due to solar panels arranged at $5 \mathrm{~m}$ height in a shed like structure on a particular land and it's shade effect on the neighbor's land. For this purpose, the shade analysis is continued on the neighbor's land on all the directions. Different shade configuration as before is constructed at a he ight of $5 \mathrm{~m}$ on owners 1 and (A in Figure 3).
Its effect on the neighbor's land (B-I in Figure 3) of 1 acre is e stimated by placing the f lat $s$ olar $p$ anels $w$ ith zero inclination on the ground surface. Such a configuration in different $\mathrm{c}$ ases is explained below $\mathrm{w}$ ith $\mathrm{v}$ arying pattern of shades as shown in Figures 3(a)-(c).

Case 7: In this case, continuous blind shade is created on 1 acre of land located $5 \mathrm{~m}$ above the ground surface with a configuration similar to case 4 . The effect of this shade is computed on the neighbour's land of 1 a cre located in all directions such as north, south, east, west and also on all the corners - north east, north west, south east and south west directions as shown in Figure 3. For the purpose of quantifying the solar radiation due to shade, flat s olar panels ar e cr eated s imilar to cas e 1 on the neighbouring lands B-I.

Case 8: In this case, the shade is at a height of $5 \mathrm{~m}$ with c onfiguration s imilar to c onfiguration of solar $\mathrm{pa}$ nels of case 2 (Figure 2(b)). As before the effect of this shade is estimated on the neighboring lands in all directions.

Case 9: In this case, the shade is at a height of $5 \mathrm{~m}$ with a configuration similar to chess board pattern ( see Figure 2(c)) s imilar to cas e-3. As b efore, it's ef fect is computed in all the directions on the neighbouring lands.

\section{Results}

All the above cases, the shade effect on the solar energy generation gave important results over one a cre of 1 and 
below the shade and also on the neighbouring land. The results derived from modelling studies are described for each case in the following.

Case 1: A s explained e arlier, in this $\mathrm{c}$ ase, the solar energy ge nerated is presented d ue t o t he s olar panels arranged in flat or ientation with $\mathrm{z}$ ero i nclination. $\mathrm{T}$ he details of the results in the form of energy generation as a function of month are presented in Figure 4.

The modelling studies showed that at Mumbai, maximum a nnual energy $(766,703 \mathrm{KW} \mathrm{h})$ is generated a nd minimum e nergy is generated for the Kolkata $\mathrm{c}$ ity $(615,897 \mathrm{KWh})$. This indicates that annual solar energy generation $\mathrm{n}$ ot $\mathrm{o}$ nly depends o $\mathrm{n}$ global i rradiation b ut also on the temperature and other parameters as well. In another study, va riation of s olar energy w ith latitude is estimated. It is observed that at a location L32 near latitude $32^{\circ} \mathrm{N}$ a nd 1 ongitude $77.57^{\circ} \mathrm{E}$ de grees, maximum annual energy with $760,686 \mathrm{KWh}$ and the least is at Kanyakumari location with $644,377 \mathrm{~K} \mathrm{Wh}$. These configurations are based on the global irradiation values for the year 1990 . This in dicates that s olar e nergy d epends on many factors such as global irradiation, temperature etc and may also be due to other parameters. It is known that solar pa nels pe rform be tter a nd y ield more e nergy a t

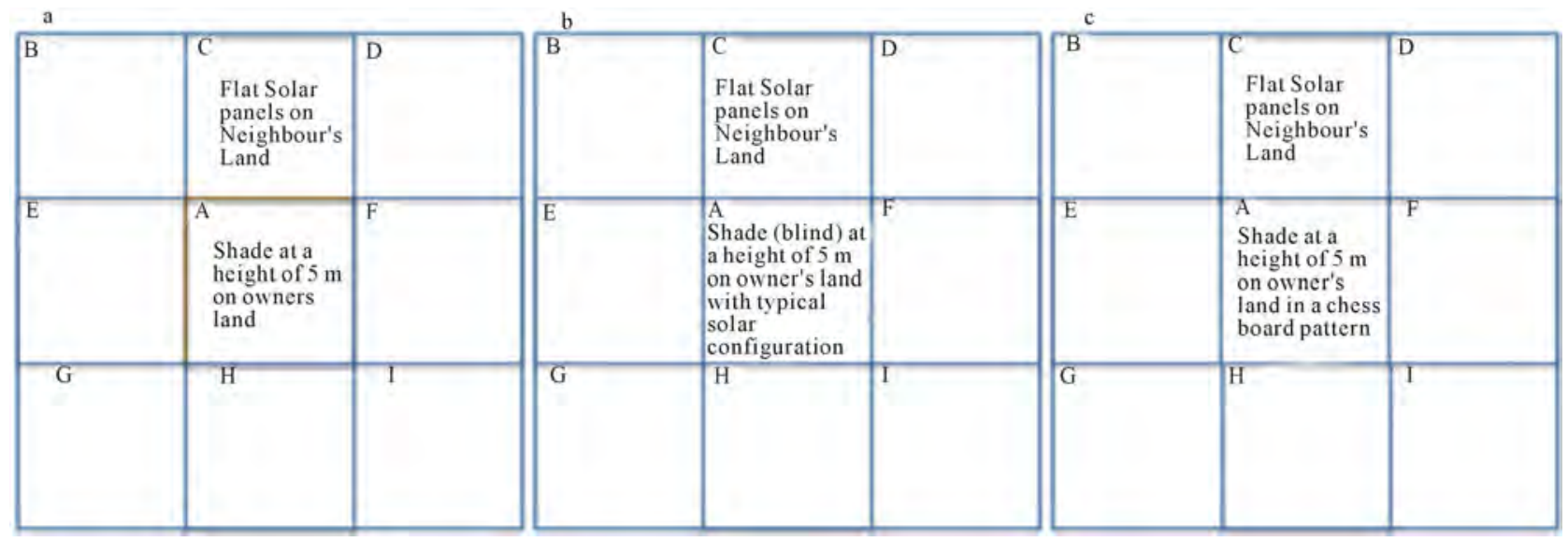

Figure 3. (a) Schematic diagram showing on e acre of th e land at th e center (A) surrounded by eight acres of land tow ards north $(C)$, south $(H)$, west $(E)$, east $(F)$, north east $(D)$, north west $(B)$, south east $(I)$, south west $(G)$. The shade is in a similar fashion as th at of case 4 (s ee Figure 2(d)). The solar panels similar to $c$ ase 1 (2a) i s placed on the lands "BCDEFGHI" to compute the effect of shade over land A over BCDEFGHI. (b) Similar to case-a except the height 5 meter shade over the land $A$ in a s imilar pattern and configuration as in the case-5 (s ee Figure 2(e)). (c) Similar to c ase-a ex cept the height 5 me ter height in a pattern of chess board with alternate panels and air gap similar to the pattern as explained in the case-6 (see Figure 2(f)).

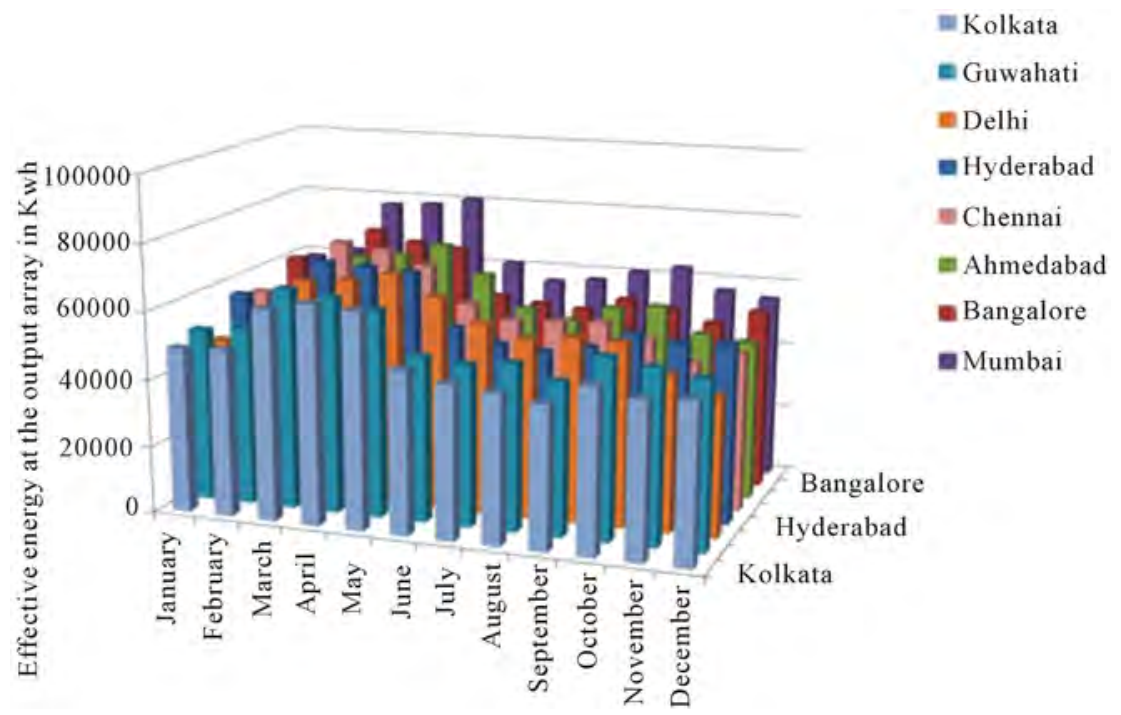

Figure 4. Annual solar energy generation graph-month wise for major cities in India. One acre of land with 1944 solar panels are placed with zero inclination in all the cities. 
lower t emperatures as co mpared to higher t emperature locations.

Figure 5 shows the energy generation in one acre of land with varying latitude for each month. The changes in s olar e nergy d o n ot show 1 inear $t$ rend $w$ ith 1 atitude. From the total annual energy values, the sequential order with i ncreasing t rend c orresponds t o the lo cations $\mathrm{L} 8$, L26, L10, L24, L28, L22, L20, L18,L12, L16, L14, L30 and L32 as shown in the figure.

In Figure 6, the total en ergy generation as a function of latitude is shown. The curve is not linear but contains two peaks - one at 32 degree latitude and the other at 14 degree latitude. This indicates that maximum solar energy g eneration is p ossible at high latitudes and close to mid latitudes of $12-18$ with a peak at $14^{\circ}$. It again indicates that s olar e nergy ge neration n ot o nly depends on horizontal global i rradiation, but a lso on other $\mathrm{p}$ arameters like local temperature as well.

For o ther cas es 2 to 9 -described b elow, Ahmedabad location is chosen as a sample. Figure 7 shows variation of energy generation for different configurations without shade by varying the pitch value. The data considered is the average global radiation for the year 1990. It may be recalled that the main theme of our study is to generate electricity $\mathrm{u}$ sing $\mathrm{c}$ ultivated a griculture 1 and. For $\mathrm{t}$ his purpose, it is important to find a relation between solar energy ge neration and global irradiation. $T$ his $r$ elation also he lps to understand the s unlight variation due to shade. Here we a ssume the sunlight is di rectly proportional to global irradiation. This assumption is reasonable as the light is considered, as one form of radiation emanating from the Sun. It is observed that solar energy generation and g lobal radiation are linearly related for Ahmedabad location (Figure 8).

Cases 2 and 3: In case-2, the solar panels are arranged in a typical fashion with $25^{\circ}$ inclination as explained before. The energy generation month wise for pitch values of 3.8, 7.6 and $11.4 \mathrm{~m}$ are presented in Figure 7. In case3 , the s olar $\mathrm{p}$ anels a re a rranged in a $\mathrm{p}$ attern $\mathrm{s}$ imilar to chess board and energy generation is shown in Figure 7. In this figure, the results of cases-1, 2 and 3 are presented for comparison. Maximum s olar e nergy is observed for flat solar p anels in o ne a cre of 1 and that contains 1944 panels without shade followed by 1728 solar panels with pitch value $3.8 \mathrm{~m}, 949$ panels distributed like chess board pattern, $864 \mathrm{p}$ anels wi th pitch va lue of $7.6 \mathrm{~m}$ and 648 panels for $11.4 \mathrm{~m}$ respectively. As expected more number of panels generate more energy. Flat solar panels has generated maximum energy followed by $3.8 \mathrm{~m}$ separated panels, checker type solar panels, $7.6 \mathrm{~m}$ pitch value and finally the least for $11.4 \mathrm{~m}$ pitch value solar panels.

Case 4, 5 and 6: In these cases, flat solar panels are kept on the ground surface and the effect of shade at $5 \mathrm{~m}$ height is kept with different patterns as shown in Figures 2(d)-(f). As explained before, the idea here is to estimate the reduction in energy generation due to shade which in turn provides information on the reduction of the sunlight on the 1 and. $\mathrm{R}$ esults derived $\mathrm{f}$ or $\mathrm{t}$ hese cas es a re shown in Figure 9.

For the sake of comparison, solar panels without shade is also shown. It can been seen that there is a considerable decrease in solar energy generation on the ground for the blind located at $5 \mathrm{~m}$ height and also for $3.8 \mathrm{~m} \mathrm{sepa-}$ rated blinds. The solar energy generation for $7.6 \mathrm{~m}$ and $11.4 \mathrm{~m}$ separated blinds have shown nearly equal values. Thus there is nearly $87 \%$ - $92 \%$ s unlight for c ase 4 as compared to no shade. In case 5 , there will be $62 \%-79 \%$ reduction of sunlight for $3.8 \mathrm{~m}$ distance blinds, $32 \%-44 \%$ reduction for $7.6 \mathrm{~m}$ separated blinds, $21 \%$ - 28\% for 11.4 $\mathrm{m}$ s eparated blinds. For cas e 6 the reduction in the sun-

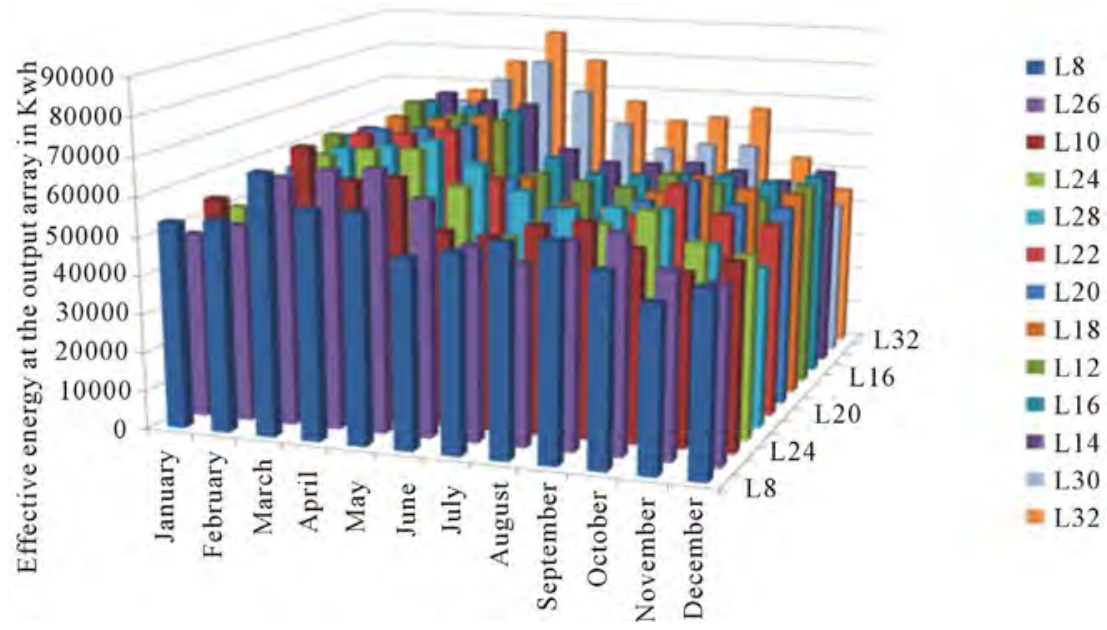

Figure 5. Annual solar energy generation graph month wise for different latitudes by fixing the longitude to $77.57 \mathrm{E}$ (Kanyakumari location). One acre has 1944 solar panels with zero inclination in different latitudes. 
light is $30 \%-40 \%$. T he reduction v alues are as compared to no shade on the solar panels. This reduction in values is limited to mid-day period between 11 am to 2 pm. Thus one can safely use the solar panels with separation of 11.4 or $7.6 \mathrm{~m}$ or like chess pattern of solar panels without much loss on the yield of the crops.

Case 7, 8, 9: Modeling on the estimation of reduction of sunlight on the neighbors land in all the eight directions ( north, s outh, e ast, west, n orth-east, n orth-west, south-east, s outh-west) if the owner has set up solar panels on his one acre of land as shown in Figure $\mathbf{1 0 .}$

The a nnual variation of e nergy ge neration with s olar panels oriented in horizontal direction on all the neighboring lands one at a time has been computed. The data considered for this computation is based on the global average radiation data the years 1981-2000 as described in $[8,15]$.

The results derived in such a configuration can be divided into five sets of curves, namely a to e as shown in Figure $\mathbf{1 0}$ for each months. As can be seen the energy generation and represented by the curves a to e is distinctly di fferent. T he energy generation i $\mathrm{n}$ gr oup of curves represented by "a" in Figure 10 shows the effects of shade on the neighboring lands B-I due to the panels at $5 \mathrm{~m}$ he ight on 1 and $\mathrm{A}$. T he curve " $\mathrm{b}$ " represents the energy generation on land A due to the effect of shade at $5 \mathrm{~m}$ height a $\mathrm{s}$ before with rows of panels separated by $11.4 \mathrm{~m}$. Similarly, curve "c" represents the energy generation on land $\mathrm{A}$ due to shade above in chess pattern and also the panels separated by $7.6 \mathrm{~m}$. Curve "d" represents the effect of shade due to panels separated by $3.8 \mathrm{~m}$. Finally, the curve " $\mathrm{e}$ " gives the result of energy generation if the shade is continuous without any gap between the rows of panels.

It is observed that there is almost nil reduction in solar energy generation on the neighboring lands in all directions for the continuous blind at $5 \mathrm{~m}$ height except one located towards the east and the west where the reduction is 1 ess than $2 \%$. The $\mathrm{s}$ ame ef fect is s een for the $\mathrm{b}$ linds located at $5 \mathrm{~m}$ height and separated by $3.8 \mathrm{~m}, 7.6 \mathrm{~m}$ and chess board pattern configuration.

\section{Discussion}

India has a vast land, mostly being used for agriculture.

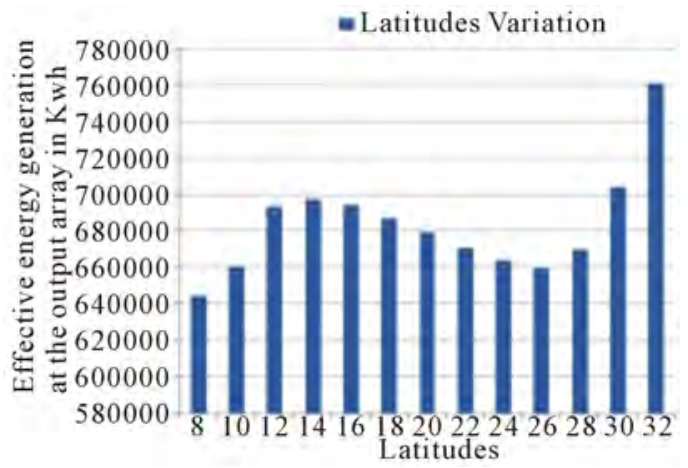

Figure 6. Total s olar e nergy g eneration for the year 1990 with latitude variation. Two maxima can be seen, one at $14^{\circ}$ and the other at $32^{\circ} \mathrm{N}$.

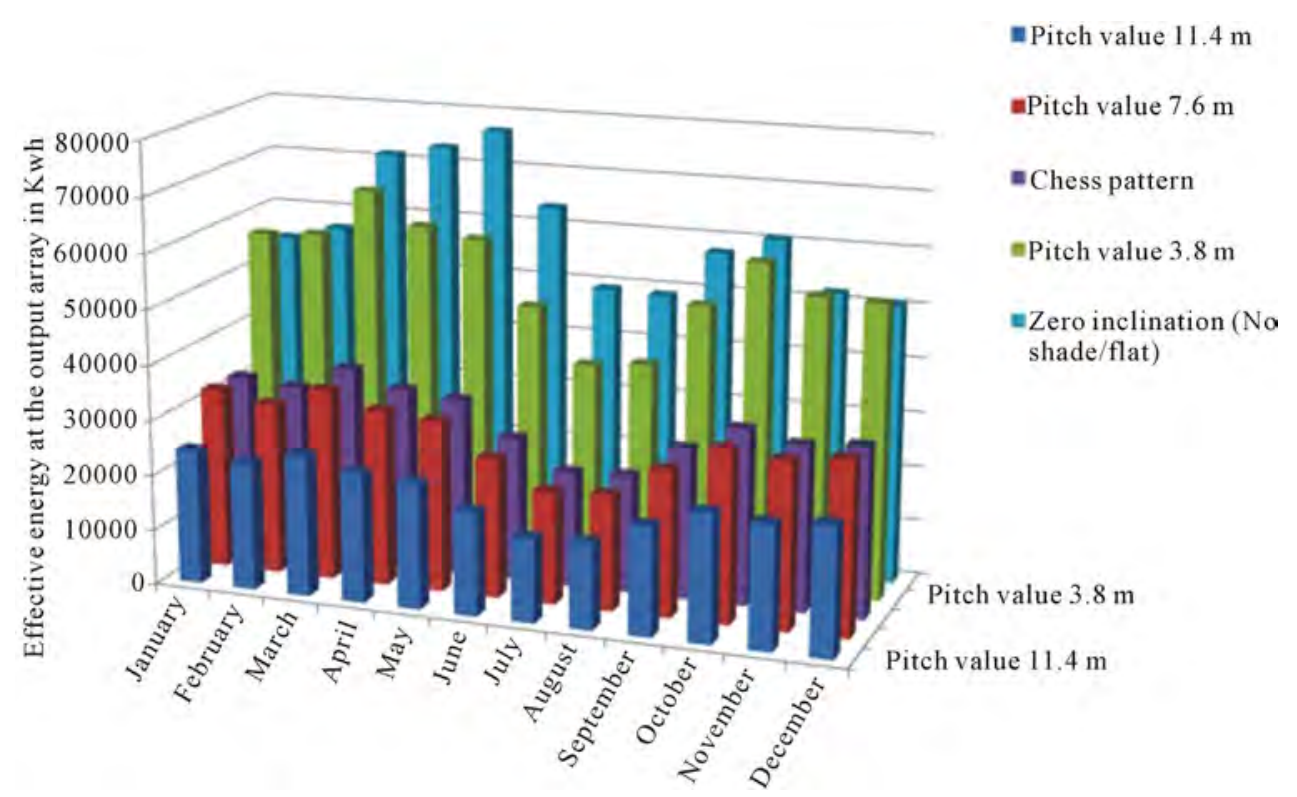

Figure 7. Annual solar energy generation-month wise for three cases-case-1, 2 and 3. Case-1 related to solar panels (1944 number) placed on the ground with zero inclination. Case-2 related to s olar panels on the ground with $25^{\circ}$ inclination with different pitch values of 3. 8/7.6/11.4 m. Case-3 related to solar panels distributed on the ground with $25^{\circ}$ inclination with chessboard like pattern. 


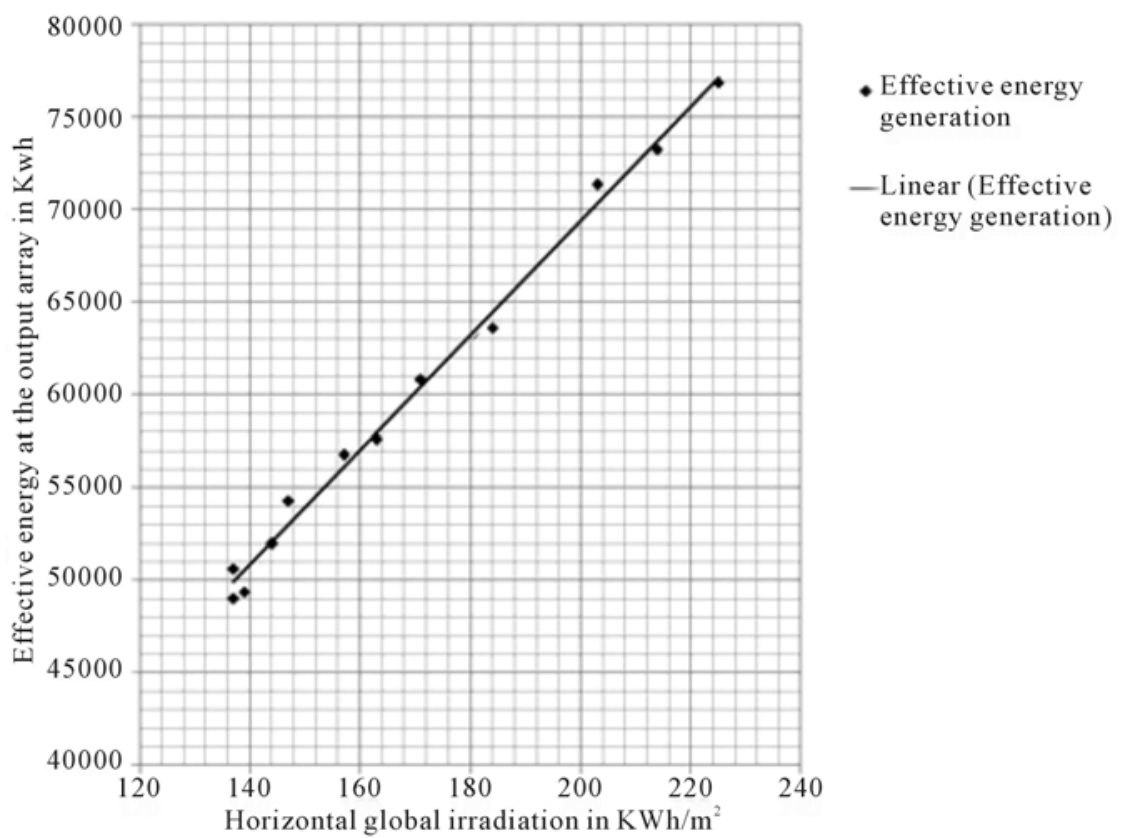

Figure 8. Effective energy of an array with horizontal global irradiation for the year 1990 . A clear linear relation is observed between the two parameters.

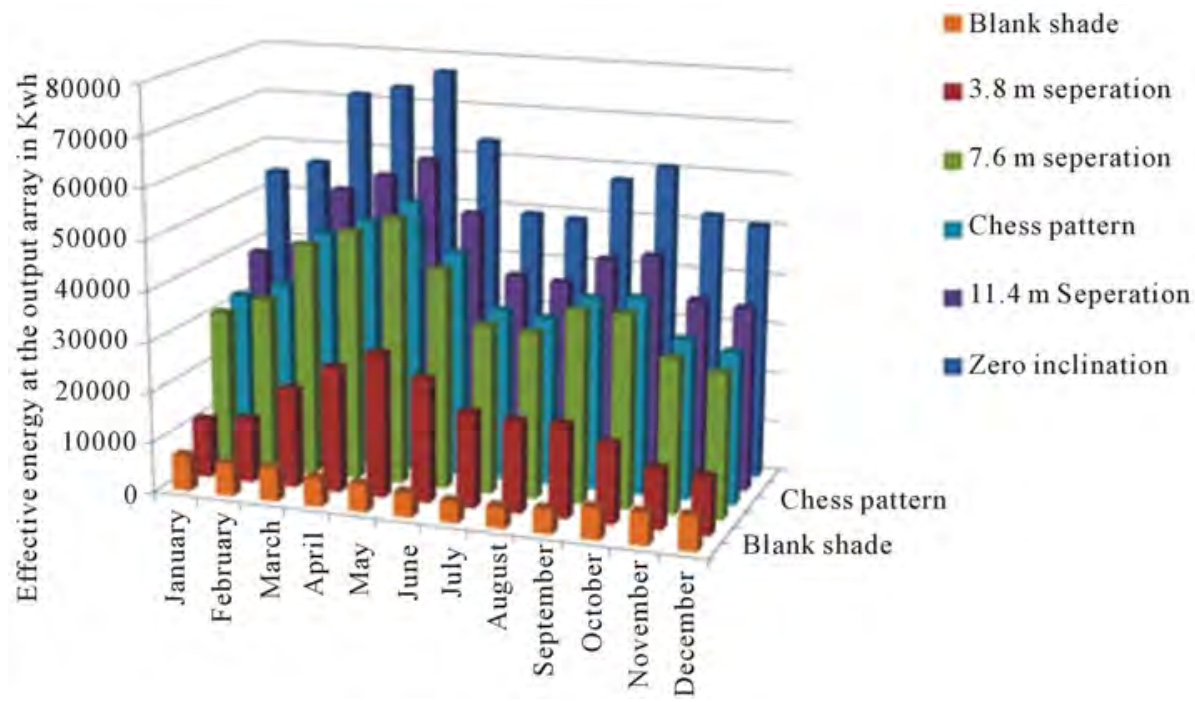

Figure 9. Annual energy generation-month wise for the cases 4, 5 and 6. Please also see Figures 2(d)-(f).

Majority of our villages are remotely located and devoid of electricity. Still more than $50 \%$ of our villages are not connected to power grid. For this purpose a new and affordable solution is p rovided through our present study as discussed in previous sections. The results presented due to different shades on the ground surface has clearly indicated that cultivable agricultural land can be used for production of solar energy without any serious ill-effects on the agricultural yield of any crop. A nominal decrease in solar radiation (sunlight) during mid day (20\% to $25 \%$ reduction) on the plants, actually may increase the yield of the crop. The reasons for this are as follows. The reduction in the sunlight during the day is maximum close to the noon period. It is well documented and known that sunlight contains ha rmful u ltraviolet A \& B (UV-A \& UV-B) rays. It starts reaching the earth surface between $11 \mathrm{am}$ to $2 \mathrm{pm}$. It is proved by the agricultural scientists that reduction in UV helps the plants to grow well [16, 17]. S imilarly a small reduction of $20 \%-30 \%$ in temperature is a lso 1 ikely $\mathrm{d}$ uring the $\mathrm{m}$ id-day pe riod. $\mathrm{T}$ his small reduction will not affect the crops.

In o ur country south Indians eat $r$ ice as their s taple 
food an $\mathrm{d} m$ ajority o $\mathrm{f}$ orth I ndians eat $\mathrm{w}$ heat as $\mathrm{t}$ heir staple food. For this purpose two states in each sector are chosen to study the global radiation and also the average temperature for different months [18]. For this purpose Andhra Pradesh, Tamil Nadu, are chosen in south India as majority of farmers grow rice in their fields and Uttar Pradesh and Punjab are chosen in north India as majority of farmers in these states grow wheat.

In Figure 11 the average temperature for the four different s tates ar e s hown a nd in Figure $\mathbf{1 2}$ the av erage global irradiation are $\mathrm{p}$ resented $\mathrm{f}$ or e ach month. It is known that during April to September months majority of farmers grow rice crop in Andhra Pradesh and Tamil Nadu $[19,20]$ a nd it is k nown that du ring O ctober to March months, the wheat crop is grown in Uttar Pradesh and Punjab [21]. It is argued here that setting up of solar panels a bove the $\mathrm{g}$ round of the a gricultural fields $\mathrm{w}$ ill actually he lps to g row more due to r eduction in U V-A and UV-B rays and slight reduction in temperature during mid-day in these states [22-24]. While these conclusions are based on the s imulation s tudies, o ne need to make a real es timation during the crop s eason at representative location in rice fields of A ndhra Pradesh and Tamil Nadu and, and also in Uttar Pradesh and Punjab. Experiments need to be conducted on crops using $11.4 \mathrm{~m}$ separated solar panels, $7.6 \mathrm{~m}$ separated solar panels and more i mportantly the ch ess board pattern like solar panels fixed at a height of $5 \mathrm{~m}$ above the cultivated land.

\section{Conclusion}

It is well known to all that most of our villages are suffering from lack of electricity. Due to this reason farmers are unable to get sufficient water for cultivation. It in-

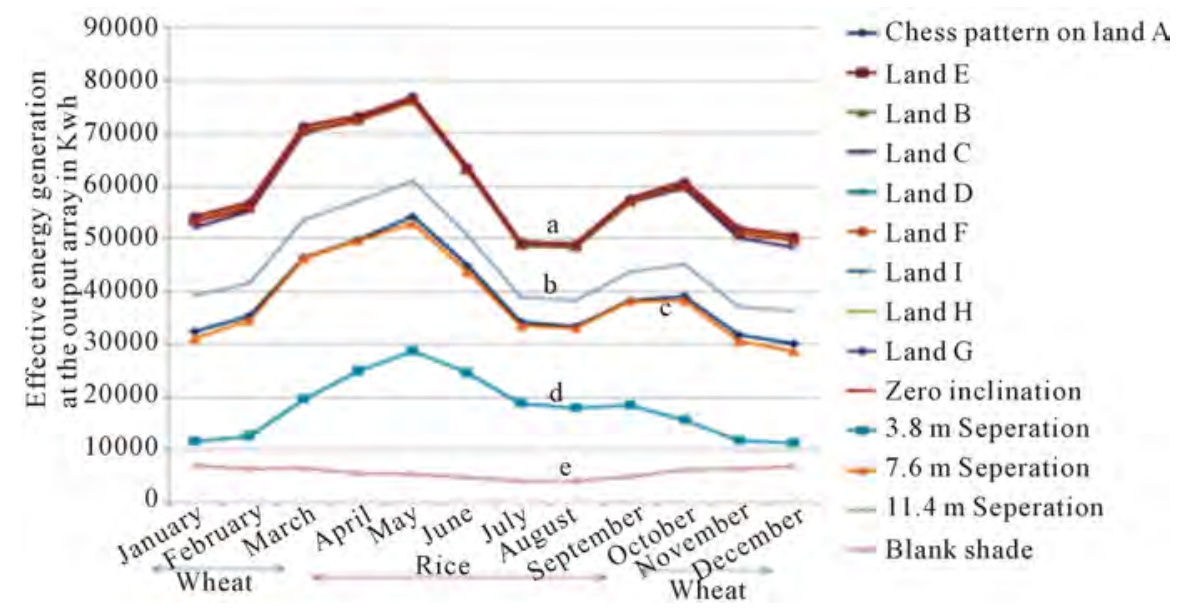

Figure 10. Annual solar energy generation month wise without shade on one acre of land in Ahmedabad region and for the shade over the lands ABCDEFGH and I. Land A has the solar panels (1944 numbers) with the shade at the height of 5 meters above the ground (see curve $A$ ). The set of curves shown $B$ in the fig provide information of solar energy generation for the lands $B$ to I due to the shade over the land $A$.

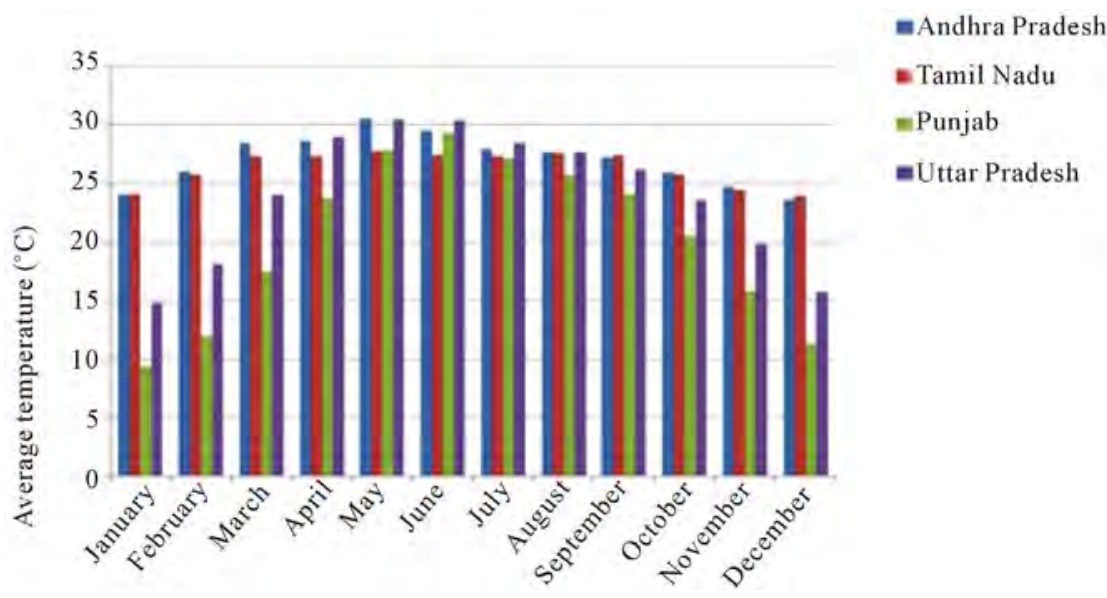

Figure 11. Annual average temperature shown in degree centigrade-month wise for four different representative states for rice (Andhra Pradesh and Tamil Nadu) and for wheat (Uttar Pradesh and Punjab). 


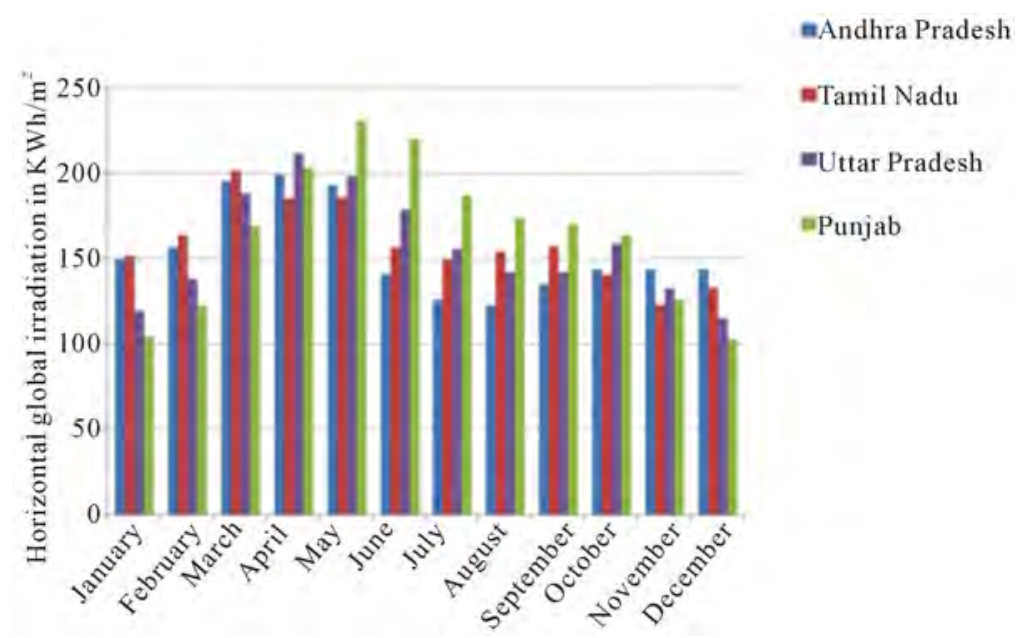

Figure 12. Annual horizontal global irradiation shown in $\mathrm{KWh} / \mathrm{m}^{2}$. mth-month wise for 4 different representative states for rice (Andhra Pradesh and Tamil Nadu) and for wheat (Uttar Pradesh and Punjab).

volves huge e xpenditure for the g overnments to $\mathrm{c}$ reate infrastructure with transmission lines to remotely located villages. An a ffordable a nd innovative s olution is presented in this paper to help major population of Indian community, $\mathrm{n}$ amely the neglected farmer community. Through m odeling s tudies, it is s hown here that s olar panels e levated at $5 \mathrm{~m}$ he ight above the cultivated land with 7.6, $11.4 \mathrm{~m}$ pitch values and a lso the solar panels arranged like chess board pattern with air gaps between the set of solar panels are more suitable. A reduction of $20 \%$ - $25 \%$ of sunlight for $11.4 \mathrm{~m} \mathrm{~s}$ eparated panels is observed. Similarly, $25 \%-30 \%$ reduction for $7.6 \mathrm{~m}$ and chess pa ttern s hades, $60 \%-80 \%$ r eduction for $3.8 \mathrm{~m}$ separated pa nels in S unlight is inferred from modeling studies. Accordingly, it is recommended to install solar panels with $7.6 \mathrm{~m}$ or $11.4 \mathrm{~m}$ separation or chess board pattern is recommended as there will be small reduction in $s$ unlight. $E$ ven $t$ his $s$ mall $r$ eduction of $s$ unlight on crops is limited to mid-day period and thus helps to reduce UV-A and UV-B radiation. It is expected that this reduction in sunlight near noon time may help the plant to grow more and give better yield. In fact, even if it affects, this can easily be rectified by placing the concave lenses in the air gaps between the solar panels to increase the sunlight. In any case, farmer is the most beneficiary as he will be using his land for dual purpose, namely, to continue the cultivation normally on the ground surface and also use his land to generate power that can be used by him for motor pumps to get water for the crops. The present i dea, if i mplemented properly, o ur farmer c ommunity will be benefited for his cultivation and also help us to reach our go al of e nergy s ecurity. Another incentive to the farmer is that he can earn by lending his land for power generation. Thus it is a win-win situation for both the farmer and the power industry de veloper. The power generated from his land can be used by the farmer on pr iority. E xcess en ergy from $h$ is $l$ and can $b$ e c onnected to the main power grid or to the micro grid such that his village is also benefitted.

\section{Acknowledgements}

We would like to thank all the scientists of solar group of GERMI for fruitful discussions. Special mention goes to Dr. Omkar J ani, Sri S agar Agarvat, Sri S hailesh P atel, Sri Souvnik Roy. The second author would like to thank the Director, GERMI and Sri Prashant Gopiyani for selection, i nitiation a nd $\mathrm{c}$ oordination of $\mathrm{t}$ his $\mathrm{p}$ roject. We would like to thank Sri Tapan Ray, VCMT, GERMI and Sri D. J. Pandian, the Chairman, GERMI for their continuous encouragement to research.

\section{REFERENCES}

[1] A. D. Goswami, "India's Solar Sunrise," Renewable Energy Focus, Vol. 13, No. 2, 2012, pp. 28-30.

[2] K. Borah, S. Roy and T. Harinarayana, "Optimization in Site Selection of W ind Turbine for Energy Using Fuzzy Logic S ystem and G IS-A Case Study for G ujarat," Open Journal of Optimization, Vol. 2, No. 4, 2013, p. 116. http://dx.doi.org/10.4236/ojop.2013.24015

[3] Ministry of N ew and Renewable Energy, Government of India, “ Jawaharlal N ehru N ational S olar Mi ssion: Towards Building SOLAR INDIA,” 2009.

http://www.mnre.gov.in/file-manager/UserFiles/mission document JNNSM.pdf

[4] A. S hankar, " The G azette o f I ndia R ESOLUTION: No.23/40/2004-R\&R (Vol. II)," New Delhi, 2005. http://www.powermin.nic.in/whats_new/national_electric ity policy.htm

[5] “2020 Rout emap for Re newable," Energy i n S cotland, The Scottish Government, p. 121. 
http://www.scotland.gov.uk/Resource/Doc/917/0118802. pdf

[6] "Philippines P lans t o R each 10 0\% Re newable E nergy within 10 Years," 2013. http://www.the9billion.com/2013/07/01/philippines-plans -to-reach-100-renewable-energy-within-10-years/

[7] S. Oyedepo, "Efficient Energy U tilization as a Tool for Sustainable Development in Nigeria," International Journal of Energy and Environmental Engineering, Vol. 3 , 2012, p. 11.

[8] P. Sharma and T. Harinarayana, "Enhancement of Energy Generation from Two Layer Solar Panels," International Journal of Energy and Environmental Engineering, Vol. 3, 2012, p. 12. http://dx.doi.org/10.1186/2251-6832-3-12

[9] P. Sh arma and T. H arinarayana, "Solar Energy Generation P otential along National H ighways," International Journal of Energy and Environmental Engineering, Vol. 4, 2013, p. 16. http://dx.doi.org/10.1186/2251-6832-4-16

[10] University of Geneva, "User's Guide, PVsyst Contextual Help," 1994-2010. www.pvsyst.com

[11] F. M. Ali-Nezhad and H. Eskandari, "Effect of A rchitectural Design of Greenhouse on Solar Radiation Interception and Crops Growth Conditions," International Journal of Agriculture and Crop Sciences, Vol. 4, No. 3, 2012, pp. 122-127.

[12] S.-C. Lee, et al., "Effect of Far-Infrared R adiation and Heat Treatment on the Antioxidant Activity of Water Extracts from Peanut Hulls," Food Chemistry, Vol. 94, No. 4, 2006, pp. 489-493. http://dx.doi.org/10.1016/j.foodchem.2004.12.001

[13] Google Earth pro v7.02013. http://www.google.com/enterprise/mapsearth/products/ea rthpro.html

[14] Pv Syst. So ftware, "NASA-SSE Satellite Data," Release 6, 1983-1993.

[15] Global M eteorological D atabase, “Meteonorm, S witzer- land," version 6.1.0.23, 2012. www.metonorm.com

[16] S. V. Krupa and H. J. Jager, "Adverse Effects of Elevated Levels of Ultraviolet (UV)-B Radiation and Ozone (O3) on Grop G rowth and Productivity," Natural R esources Management and Environment Department, 1996. http://www.fao.org/docrep/w5183e/w5183e09.htm

[17] F. B azzaz and W. Sombroek, "Global Climate C hange and Agricultural P roduction," Cha pter 7-Adverse Effects of Elevated Levels of Ultraviolet UV (B) Radiation and Ozone on Crop Growth and Productivity, No. W5183, John Wiley \& Sons Ltd., 1996. http://www.fao.org/docrep/W5183E/W5183E00.htm

[18] A Re port on A goro Metorology, "Temperture and P lant Growth," TNAU A gritech P ortal, T amilnadu A gricutlral University, Coimbatore, 2013.

http://www.agritech.tnau.ac.in/agriculture/agri_agromete orology temp.html

[19] C. Che ralu, "Status P aper on R ice in A ndhra Pradesh," 2013.

http://www.rkmp.co.in/sites/default/files/ris/rice-state-wis e/Rice $\% 20$ State $\% 20$ Wise $\% 20$ Andhra\%20Pradesh_0.pdf

[20] Rice in Tamil Nadu, "Main Regions and Seasons," 2013. http://advanceagripractice.in/crop-locations/rice-in-tamiln $\underline{\mathrm{adu} /}$

[21] "TNAU A gritech P ortal: Crop Improvement," Seasons, 2013. http://www.acx.in/crop/wheat.html

[22] A. B alasubramainam, "Microclimate and Its U tilization in Indian Farming," ILEIA, Vol. 3, No. 3, 1987, p. 9.

[23] C. Campillo, R. Fortes and M. H. Prieto, "Solar Radiation Effect on Crop Production," Chapter 11, 2010, pp. 167194. www.intechopen.com

[24] V. Janet and P. K. Sharma, "Photo Inhibition and Photosynthetic A cclimation of Rice P lants Grown under Different Light Int ensities and Photo Inh ebited un der F ield Conditions," Indian Journal of Biochemistry \& Biophysics, Vol. 46, 2009, pp. 253-260. 